\title{
Effect of group size and health status on behavior and feed intake of multiparous dairy cows in early lactation
}

\author{
Margit Bak Jensen ${ }^{* 1}$ and Kathryn L. Proudfoot† \\ *Department of Animal Science, Aarhus University, Blichers Allé 20, 8830 Tjele, Denmark \\ †Veterinary Preventive Medicine, The Ohio State University, 1920 Coffey Road, Columbus 43214
}

\begin{abstract}
Dairy cows in early lactation are often housed in a large group, where they may have to compete for access to feed and space. However, a cow's ability to compete may be impaired due to production disease, and housing in a small group with minimal competition may be beneficial for cow welfare. The aim of this study was to investigate the effect of group size and health on social and feeding behavior of cows during the first $3 \mathrm{~d}$ after introduction to a new group. Data included 54 multiparous Holstein-Friesian cows that were moved from an individual maternity pen and individually joined an existing group pen for 6 (N6) or 24 cows (N24) on d 4 after calving. Cows were considered sick if they were diagnosed with and treated for milk fever, mastitis, or retained placenta, diagnosed with subclinical ketosis or metritis within $3 \mathrm{~d}$ of calving, or were diagnosed and treated for any other infection $(\mathrm{n}=22$; balanced across treatments). Stocking density of both pens was $100 \%$ at the feeding and lying areas. Behavioral data were collected from video recordings during the $1 \mathrm{~d}$ after introduction to the group pen, as well as via electronic feed bins and leg-attached accelerometers during the first 3 d after introduction to the group pen. No interactions between health status and group size were discovered. During the $1 \mathrm{~d}$ after introduction, N6 cows displaced other cows from feed less frequently than N24 cows (1.22 vs. 5.76 times $/ 24 \mathrm{~h}$ ), were less likely to access feed after a displacement (replacement; 0.29 vs. 1.67 times $/ 24 \mathrm{~h}$ ), and were less frequently being butted by another cow (0.42 vs. 1.69 times/24 h). Second-parity cows received more head butting than later-parity cows. Data obtained from feed bins showed that the number of replacements peaked on d 2 after introduction to the group pen. During the first $3 \mathrm{~d}$ we observed no effect
\end{abstract}

Received April 17, 2017.

Accepted August 10, 2017.

${ }^{1}$ Corresponding author: MargitBak.Jensen@anis.au.dk of group size on DMI, but sick cows ate less than cows that were not sick (15.2 vs. $16.6 \mathrm{~kg}$ of DM/d). However, cows in N6 visited the feeder less often (42.4 vs. 55.6 times/d). Over the $3 \mathrm{~d}$ after introduction DMI and feeding time increased, whereas feeding rate decreased. Lying time and the number of lying bouts increased from $\mathrm{d} 1$ to 2 . The number of steps decreased over days, but the number of steps was higher among N24 than N6 cows on $d 1$ and d 2. Results suggest that cows experience less competition when moved to a smaller group after calving regardless of health status. Thus, minimizing competition by housing dairy cows in a small group for the first days after calving may improve cow welfare under commercial conditions.

Key words: feeding behavior, group size, regrouping, social behavior

\section{INTRODUCTION}

The welfare of dairy cows in early lactation is a concern, both because of the way they are managed and housed and because of their high risk of disease after giving birth. During the transition from gestation to lactation, dairy cows experience several social stressors including separation from their calf and regrouping with a new group of cows after calving. These cows are also at high risk of reproductive and metabolic diseases (reviewed by Mulligan and Doherty, 2008), and those that become ill have impaired ability to compete for feed compared with those that remain healthy after calving (e.g., Huzzey et al., 2007; Goldhawk et al., 2009). To assure that cows are able to obtain sufficient feed and rest after calving, providing cows that have just given birth unrestricted access to feed and lying space is important, and management and housing should ensure sufficient access to these resources to reduce social competition.

A main social challenge for cows after calving is their introduction into a new pen and group of cows. Regrouping is known to cause increased agonistic behavior because new dominance relationships have to be established among the newcomer and her new group 
mates. For instance, on the first day after mid-lactation cows were individually moved into an established group, they were displaced from feed more than twice as often as the previous $3 \mathrm{~d}$ (von Keyserlingk et al., 2008). Moving cows into a novel pen may pose a special challenge in terms of accessing feed, as cows that were moved into a novel pen consumed less feed and initiated more displacements from the feed bunk compared with those cows that were already in the pen (Schirmann et al., 2011).

The size of the group that a cow is being introduced to may affect her behavior; a cow introduced into a larger group may experience more agonistic behavior compared with a cow introduced into a smaller group, as the cow in the larger group may have to compete with more cows for access to resources. However, in a study using cows in mid lactation, Telezhenko et al. (2012) found that reducing the number of lactating dairy cows in a pen from 12 to 6 cows did not affect the level of aggression. Although few studies have examined the effect of group size in adult cattle (Rind and Phillips, 1999; Telezhenko et al., 2012), young dairy calves kept in larger groups (12 vs. 24 calves: Jensen, 2004; 2 vs. 6 calves: Jensen and Budde, 2006) increased the rate of milk ingestion, which suggests that competition for milk was higher the larger the group.

Some evidence has shown that housing postparturient cows in separate pens and smaller groups may reduce the level of competition and improve the social environment for healthy cows. For example, Burow et al. (2009) found that postparturient cows moved to a group of about 9 cows have fewer social interactions in the first few hours after introduction compared with those moved to the main lactating herd (group size approximately 130). In addition, housing postparturient cows in a separate pen from the milking herd after calving increased milk yield among the primiparous cows (Østergaard et al., 2010). Research is still needed to determine the effect of moving healthy and ill cows into a novel pen of various group sizes after calving. The aim of our study was to investigate the effect of group size and health status on the social, feeding, and lying behavior of postpartum cows during the first $3 \mathrm{~d}$ after introduction to a group.

\section{MATERIALS AND METHODS}

The experiment took place at the Aarhus University's Cattle Research facility in Foulum, Denmark, between September 2011 and February 2012. Cows were cared for according to a protocol approved by the Danish Animal Experiments Inspectorate, Ministry of Justice, Copenhagen, Denmark.

\section{Animals, Housing, and Treatments}

The experiment began with 79 multiparous Danish Holstein dairy cows, but only 54 were included in the final analysis (described in a later section). Approximately 2 wk before expected calving date, cows were assigned to 1 of 6 blocks and 1 of 2 postcalving treatments [ 6 cows per pen (N6) or 24 cows per pen (N24)]. Each block included an average of 14.7 cows (SD = 1.5 , minimum $=12$, maximum $=16$ ) that were housed in 1 of 2 deep-bedded straw pack pens [each $9 \times 15$ $\mathrm{m}$; see Proudfoot et al. (2014) for a detailed description of these pens]. Cows were moved into individual calving pens located directly adjacent to the bedded pack pens [median (interquartile range)] 21 (4 to 73) h before calving (except for 4 cows that were moved into the pen within $6 \mathrm{~h}$ after calving). In both the bedded pack pens and individual pens, cows were fed a TMR ad libitum with a forage to concentrate ratio of 79:21 (\% DM basis) twice daily at 1000 and $1700 \mathrm{~h}$.

After calving, cows were kept in the individual calving pen with their calves for $3 \mathrm{~d}$, fed a postpartum TMR ad libitum with a 60:40 forage to concentrate ratio (\% DM basis), and were milked twice daily at 0600 and $1800 \mathrm{~h}$ using a manual milking machine. At $1000 \mathrm{~h}$ on the fourth day and [median (range)] 115 (84 to 129) h after calving, cows were moved to a neighboring building and individually introduced into 1 of 2 treatment pens ( $\mathrm{N} 6$ or N24; both pens were located in the same building), whereas calves were moved to pens in a separate building 15 to $30 \mathrm{~min}$ later. The 2 treatment pens were equipped with freestalls (1 stall $/ 1$ cow) fitted with 35-mm-thick rubber mattresses (Fremtiden Staldinventar A/S, Langå, Denmark), bedded daily with a thin layer of sawdust, and Insentec electronic feeding bins (Insentec B.V, Marknesse, the Netherlands; 1 feed bin/1 cow; validated by Chapinal et al., 2007). Cows were fed a TMR ad libitum with a forage-to-concentrate ratio of 60:40 (\% DM basis). Feeding bins were filled by a feeding robot (Cormall, Sønderborg, Denmark, Special Robot M3, 0780032022) maintaining a minimum of $2 \mathrm{~kg}$ and a maximum of 25 $\mathrm{kg}$ of TMR in each bin. Bins were cleaned Monday, Wednesday, and Friday between 0700 and $0900 \mathrm{~h}$ and, after that, all bins were filled again (with the maximum of $25 \mathrm{~kg}$ ) no later than $1000 \mathrm{~h}$. All cows had previous experience with Insentec bins. Cows were milked twice daily between 0515 and $0600 \mathrm{~h}$ and again between 1530 and $1615 \mathrm{~h}$ in a herringbone milking parlor. Cows were moved to the milking parlor with their group and groups were not mixed at milking. The distance to the milking parlor was the same for both groups. The social composition of the treatment pens were dynamic, as cows were moved in on the fourth day after calving and 
were moved out after 14 to $18 \mathrm{~d}$ in the treatment pen to maintain the stocking density of both pens at $100 \%$ (1 cow per lying stall and feed bin). The space per cow in both pens was the same. Data only report the first $3 \mathrm{~d}$ after introduction to the pen. Only 1 cow was introduced in any of the 2 groups on the same day. The same number of experimental cows was introduced to both treatments. For 8 cows in N24 and 5 cows in N6, a new experimental cow was introduced on d 2 or 3 of the previously introduced experimental cow.

\section{Exclusion Criteria and Health Status}

Of the 79 cows originally included in the study, 25 were removed from the final data set. Cows were excluded from the experiment if they had calved in the group-bedded pack pen during the first month of the study $(\mathrm{n}=3$; after the first month cows that calves in a group pen was moved to an individual maternity pen immediately after calving and this was no longer an exclusion criteria), experienced a difficult calving (calving was assisted) or had twins $(\mathrm{n}=7)$, were moved into a hospital pen with a severe illness within the first $3 \mathrm{~d}$ after calving $(\mathrm{n}=2)$, were not able to access feed bins during the first hours after introduction to group pens due to human error or power failure $(n=6)$, or had missing feed bin data during 1 of the first $3 \mathrm{~d}$ due to power failure $(\mathrm{n}=7)$. Of the 54 remaining cows [average $\mathrm{BW}=623$ (528 to 752 ) kg; mean (range)], 27 were in N6 (11 cows in 2nd parity, 5 cows in 3rd parity, and 11 cows in later parities) and 27 were in N24 (9 cows in 2nd parity, 9 cows in 3rd parity, and 9 cows in later parities). Cows of all parties had experience of being grouped with more mature individuals. The video data included 50 cows, because 2 cows were excluded from each of the 2 treatments due malfunction of camera or power failure (Table 1). A subset of cows were each fitted with an accelerometer, and data were obtained from 40 of these cows [21 cows in N6 (11 not sick and 10 sick) and 19 cows in N24 (13 not sick and 6 sick)].

Health status was determined using veterinary exams conducted when the farm manager suspected a cow was ill ( $\mathrm{n}=15$ cows), daily assessments of milk by milkers, and a health examination conducted by 1 of 2 trained

Table 1. Number of animals in groups of 6 (N6) and 24 (N24) cows, and categorized as either not sick or sick within $3 \mathrm{~d}$ of calving (numbers in brackets are number of animals included in the data obtained from video recordings)

\begin{tabular}{lccc}
\hline Item & N6 & N24 & Total \\
\hline Not sick & $15(14)$ & $17(15)$ & $32(29)$ \\
Sick & $12(11)$ & $10(10)$ & $22(21)$ \\
Total & $27(25)$ & $27(25)$ & $54(50)$ \\
\hline
\end{tabular}

experimenters on d 3 after calving (the day before the cows were moved into the treatment pen). During each health examination, a vaginal exam was performed to determine the presence of acute metritis [4-point scoring system; see Huzzey et al. (2007) for a description of this scoring system], and a blood sample from the tail vein was drawn to determine signs of clinical and subclinical ketosis (Precision Xtra Ketone Glucose and Ketone Monitoring System, Abbott Laboratories, Chicago, IL; validated by Iwersen et al., 2009). Signs of mastitis were recorded twice daily by the milker based on the color and consistency of the milk.

Data collected from the veterinarian, milker, and the health examination $3 \mathrm{~d}$ after calving were used to categorize animals into a dichotomous health variable (sick or not sick) before entry into the treatment pen (N6 or N24). Cows were considered sick if they had (1) a vaginal exam score of 2 or greater on d 3 after calving $(\mathrm{n}=4),(2)$ a blood ketone level $\geq 1.2 \mathrm{mmol} / \mathrm{L}$ on $\mathrm{d}$ 3 after calving $(\mathrm{n}=4)$, (3) signs of mastitis recorded by the milker daily based on the color and consistency of the milk on or before d 3 after calving $(n=4)$, (4) clinical signs of hypocalcemia diagnosed by the veterinarian on 1 after calving $(\mathrm{n}=3),(5)$ clinical signs of pneumonia diagnosed by the veterinarian on $\mathrm{d} 2$ after calving $(\mathrm{n}=1),(6)$ a fever $(>39.5 \mathrm{C})$ without other clinical signs diagnosed by a veterinarian on $\mathrm{d} 1$ after calving $(\mathrm{n}=2),(7)$ retained placenta diagnosed by the veterinarian on $\mathrm{d} 1$ after calving $(\mathrm{n}=1)$, (8) severe lameness caused by interdigital dermatitis diagnosed by the veterinarian on $\mathrm{d} 1$ after calving $(\mathrm{n}=1)$, or (9) a combination of mastitis and a blood ketone level greater than or equal to 1.2 on $\mathrm{d} 3$ after calving $(\mathrm{n}=$ 2 ). Every sick cow represented only 1 sick condition, except for the 1 cow with the combination of mastitis and a high blood ketone level. A total of 22 cows were categorized as sick before entry into the treatment pen; the remaining 32 cows had no clinical or subclinical signs of illness before d 3 and were considered not sick (Table 1). The sick group consisted of 7 cows of 2 nd parity, 6 cows of 3rd parity, and 9 cows of later parities.

Cows diagnosed with mastitis were treated with an injectable antibiotic, chosen and given by the veterinarian, on the day of diagnosis according to standard veterinary procedures including 1 of 3 treatments: penicillin, $100 \mathrm{~mL}$ (Penovet; Boehringer Ingelheim Pharma GmbH \& Co. KG, Ingelheim, Germany); amoxicillin, $150 \mathrm{~mL}(150 \mathrm{mg} / \mathrm{mL}$ Curamox; Boehringer Ingelheim Denmark A/S, Copenhagen, Denmark); or sulfadiazine $200 \mathrm{mg}$ and trimethoprim $40 \mathrm{mg}, 150 \mathrm{~mL}$ (Norodine 24\%; Norbrook Laboratories Ltd., Corby, UK). Treatments for mastitis were repeated for $3 \mathrm{~d}$. Cows diagnosed with pneumonia and those with fevers were provided an injectable antibiotic given by the vet- 
erinarian on the day of diagnosis according to standard veterinary procedures, including alamycin $300 \mathrm{mg} / \mathrm{mL}$, 100-mL dosage repeated for $3 \mathrm{~d}$ (Norbrook Laboratories Ltd.). Cows with hypocalcemia were provided a calcium supplement intravenous by the veterinarian on the day of diagnosis (Calcijet; Norbrook Laboratories Ltd.). The cow with retained placenta was treated intrauterine with an antibiotic by the veterinarian on the day of diagnosis (Terramycin, Phibro Animal Health Corporation, Teaneck, NJ; 25 g of uteritorie containing $500 \mathrm{mg}$ of oxytetracycline hydrochloride). Cows with mastitis, lameness, and pneumonia were also given a nonsteroidal antiinflammatory drug on the day after diagnosis [either flunixin meglumine, $50 \mathrm{mg} / \mathrm{mL}, 20$ $\mathrm{mL}$ dosage (Finadyne Solution; MSD Animal Health, Milton Keynes, UK) or Metacam, 20-mg/mL solution, 15-mL dosage (Boehringer Ingelheim Pharma GmbH \& Co. KG)].

\section{Behavioral Data Collection}

Feeding, lying, and social behavior were recorded during the first $3 \mathrm{~d}$ after cows were moved into the treatment pens at $1000 \mathrm{~h}$ on $\mathrm{d} 4$ after calving. To account for diurnal changes in behavior, each day was defined as the interval from 1000 to $0959 \mathrm{~h}$ the next day.

For the first $1 \mathrm{~d}$ after cows were introduced to the treatment pen, detailed social behaviors (Table 2) were recorded by 1 observer using video data (real time) captured from digital video cameras (TVCCD-624, Monacor UK Ltd., Milton Keynes, UK) mounted above each pen. In addition, the duration from introduction until the focal cow accessed a feed bin for the first time was recorded (latency to feed).

Feeding behavior was recorded automatically from the electronic feed bins. The feed bins recorded the amount of feed consumed by each cow and the amount of time she spent feeding during each visit to the bin.
These data were edited to remove extreme outliers, using the methodology described by Bossen et al. (2009), before they were used to calculate the daily feed intake $(\mathrm{kg}$ of $\mathrm{DM} / \mathrm{d})$, daily feeding time $(\mathrm{min} / \mathrm{d})$, average feeding rate ( $\mathrm{g}$ of $\mathrm{DM} / \mathrm{min}$ ), and feed intake during each visit to the feed bins ( $\mathrm{kg}$ of DM/visit) for each cow on each of the $3 \mathrm{~d}$ after introduction to the treatment pen. Social replacements from the feed bins were also recorded automatically from the electronic feeding system using a method validated by Huzzey et al. (2014). A cow was recorded to be an actor in a replacement when she entered the feed bin within $10 \mathrm{~s}$ after another cow (the reactor) left the same feed bin.

Lying behavior was recorded automatically using IceTag accelerometers (IceRobotics Ltd., Edinburgh, Scotland, UK; http://www.icerobotics.com). Accelerometers were affixed to 1 hind leg of each cow on the day that cows entered the precalving pen and were removed 14 to $18 \mathrm{~d}$ after calving, when cows were removed from the experimental pens. The accelerometers recorded the posture of the cow (standing or lying) every $1 \mathrm{~s}$ and recorded the number of steps taken continuously. All cows walked the same distance to the milking parlor and steps associated with milking were included in the data. Data retrieved from the accelerometers were summarized per cow and day to determine daily lying time (h/d), the number of lying bouts per day (transitions from standing to lying, frequency/d), and the number of steps taken per day (frequency/d) for each cow.

\section{Statistical Analysis}

All statistical analyses were performed with SAS software (version 9.4; SAS Institute Inc., Cary, NC) using the cow as the experimental unit. Data were screened for normality by visual inspection of residual plots, and behavioral variables that could not be assumed normally distributed were transformed to normality by the square root or the natural logarithm. Homogeneous

Table 2. Ethogram of social behaviors recorded by continuous focal animal sampling during the first $1 \mathrm{~d}(24 \mathrm{~h})$ after each cow entered the treatment pens $4 \mathrm{~d}$ after calving

\begin{tabular}{ll}
\hline Social behavior & Definition \\
\hline Displace cow from feed bin & $\begin{array}{l}\text { Cow butts or pushes head (with physical contact) against any body part of another cow resulting in the } \\
\text { other cow removing its head from the feed bin }\end{array}$ \\
$\begin{array}{l}\text { Cow places head in the feed bin that it has just displaced another cow from (within 10 s) } \\
\text { Being displaced from feed bin }\end{array}$ & $\begin{array}{l}\text { Cow is being butted or pushed (with physical contact) on any body part resulting in the focal cow } \\
\text { removing its head from the feed bin }\end{array}$ \\
Cisplace cow from freestall & Cow butts head or pushes head or body (with physical contact) against any body part of another cow \\
& while this other cow is standing (at least front hooves in stall) or lying in a freestall, which results in \\
this other cow leaving the stall & Cow enters the freestall that it has just displaced another cow from (within 10 s) \\
Replace cow in freestall & Cow butts with its forehead against another cow's side of head, neck, or body \\
Head-butt cow & Cow butts with its forehead against another cow's forehead while the 2 are standing facing each other \\
Head-to-head fight & Cow is being head-butted on side of head, neck, or body by another cow \\
Being head-butted &
\end{tabular}


variance was assumed based on visual inspection of residuals plotted against the predicted values.

Social Behavior During 1 d After Introduction to Group Pen. Among the video data collected during the first day after introduction to the group, the effect of health status and treatment on the number of times cows displaced other cows from the feed bins, replaced other cows in the feed bins, were displaced from the feed bins, head-butted another cow, were head-butted by another cow, and the latency to eat were analyzed using a mixed model (PROC MIXED) that included the fixed effects of treatment (N6, N24), parity (2nd, 3rd, $>3$ rd), health status (not sick, sick), and treatment $\times$ health status. Block $(1,2, \ldots, 6)$ was included as a random effect. The latency to eat was transformed using the natural logarithm, and the remaining variables were transformed by the square root method before analysis.

Due to many zero observations, the variables displacing cow from freestall, replacing cow in freestall, and head-to-head fights were transformed to binary variables $(1=$ the cow performing the behavior at least once; $0=$ the cow not performing the behavior), and the number of cows performing these behaviors was analyzed for the effect of first group (N6, N24) and then health status (not sick, sick) by Chi-squared analysis.

Behavior During the First $3 d$ After Introduction to the Group Pen. The variables feed intake, feeding time, feeding rate, feed intake per visit, replacements, and being replaced, as well as the accelerometer variables lying time, lying bouts, and steps were analyzed using a mixed model (PROC MIXED) including fixed effects of treatment (N6, N24), parity (2nd, 3rd, $>3$ rd), health status (not sick, sick), day after introduction $(1,2,3)$, and the interactions treatment $\times$ health status, treatment $\times$ days, health status $\times$ days, and treatment $\times$ health status $\times$ days. Cow and block (1, $2, \ldots, 6)$ were considered as random effects and the correlation between repeated observations on the same cow across days was modeled using an autoregressive covariance structure. Multiple comparisons between least squares means were conducted using the contrast statement.

\section{RESULTS}

\section{Social Behavior During 1 d After Introduction to Group Pen}

Effect of Group Size. During the first day after introduction to the group pen, N6 cows displaced other cows from feed bins less frequently than N24 cows, were less likely to access feed after a displacement, and were less frequently head-butted by other cows (Table 3). No effect of treatment was found for other social behaviors measured, including cows being displaced from feed or latency to feed, but N6 cows tended to head-butt other cows less frequently than N24 cows (Table 3). Fewer cows in N6 were involved in head-to-head fights compared with cows in N24 [ $44 \%(11 / 25)$ in N6 vs. $96 \%$ $(24 / 25)$ in N24; chi-squared $(\mathrm{df}=1)=16.1 ; P<0.01]$.

Effect of Health Status. Across group size, fewer sick cows displaced other cows from freestalls compared with cows that were not sick $[71 \%(15 / 21)$ vs. $93 \%$ $(27 / 29)$; chi-squared $(\mathrm{df}=1)=4.26 ; P<0.05]$. No effects of health status were found for the number of cows that replaced another cow in a freestall. Sick cows tended to have a longer latency to eat after introduction to the treatment pen compared with those that were not sick $\left[3.53( \pm 0.51)\right.$ vs. $2.47( \pm 0.44) ; \mathrm{F}_{1,39}=$ $3.02 ; P=0.09]$. Back transformed estimates are 34 and 12 min, respectively.

Effect of Parity. We noted an effect of parity on head-butting; second-parity cows received more headbutts than third- or later-parity cows $[1.38( \pm 0.26)$, $0.58( \pm 0.27)$, and $\left.0.95( \pm 0.25) ; \mathrm{F}_{1,39}=4.20 ; P<0.05\right)$.

Table 3. The effect of group size [cows housed in groups of 6 (N6) or 24 (N24)] on social behavior recorded via video during $1 \mathrm{~d}$ after introduction to the group pen, as well as the effect of group size on social and feeding behavior recorded via feed bins during the first $3 \mathrm{~d}$ after introduction

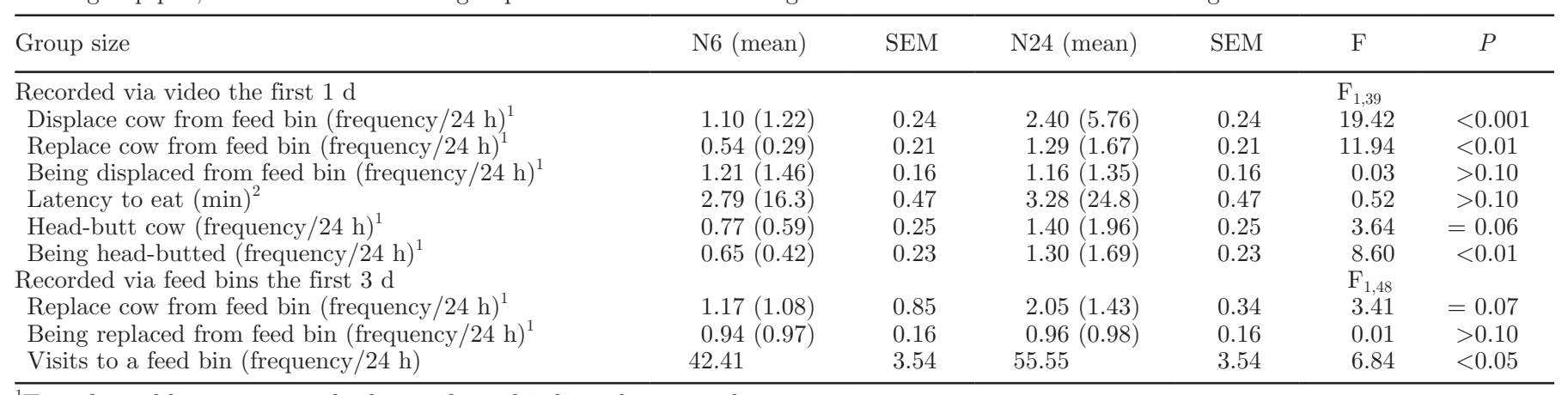

${ }^{1}$ Transformed by square root back transformed indicated in parentheses.

${ }^{2}$ Transformed by natural logarithm back transformed indicated in parentheses. 
Back-transformed estimates were 1.93, 0.34 and 0.90 events $/ 24 \mathrm{~h}$ for cows in $2 \mathrm{nd}$, 3rd, and $<3$ rd parity.

Interaction Between Health Status and Group Size. No interactions between health status and group size were discovered for any of the continuous social behavior variables.

\section{Behavior During the First 3 d After Introduction to the Group Pen}

Effect of Group Size. Data collected from the electronic feed bins during the first $3 \mathrm{~d}$ after introduction to the group pen showed that N6 cows tended to replace (actor) other cows less often than N24 cows; however, we found no differences between treatments in the number of times a cow was being replaced (reactor; Table 3). We observed no effect of group size on DMI or lying time.

Effect of Health Status. Sick cows had a lower DMI than not sick cows $[15.22( \pm 0.41)$ vs. $16.62( \pm 0.34) \mathrm{kg}$ of $\left.\mathrm{DM} / 24 \mathrm{~h} ; \mathrm{F}_{1,47}=7.08 ; P<0.01\right]$. We noted no effect of health status on the calculated feeding rate.

Effect of Day and Interactions with Day. The effect of days after introduction is shown in Table 4. The frequency of cows replacing other cows from feed bins, and the frequency of cows being replaced from the feed bins by other cows increased from d 1 to 2. Dry matter intake and feeding time increased across all $3 \mathrm{~d}$, whereas feeding rate decreased over days.

We found a treatment $x$ day interaction for the number of visits to a feed bin $\left(\mathrm{F}_{2.102}=3.23 ; P<0.05\right.$; Figure 1), whereby feeding visits were lower in N6 on d 1 and 2, but not d 3, compared with N24. Time spent lying increased markedly over days, whereas the number of lying bouts increased from $\mathrm{d} 1$ to 2 . The number of steps decreased over days in both treatments, but

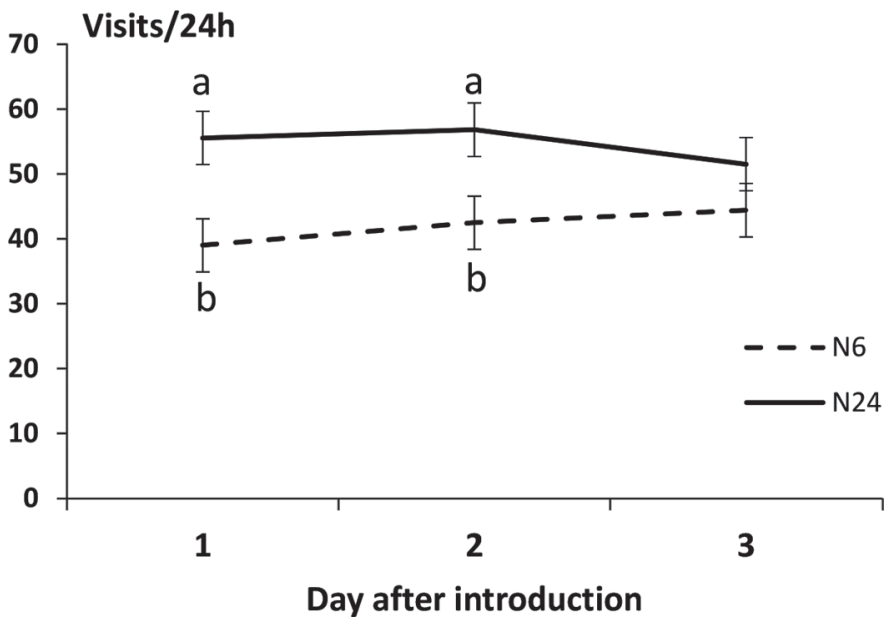

Figure 1. Number of daily visits to a feed bin (mean \pm SEM) of cows $(\mathrm{n}=54$ ) on treatments N6 (introduced to a group of 6 cows on $\mathrm{d}$ 4 after calving) or N24 (introduced to a group of 24 cows on d 4 after calving). For each day different letters $(\mathrm{a}, \mathrm{b})$ indicate significant differences $(P<0.05)$ between treatments on that day.

was higher on d 1 and 2 in N24 cows compared with $\mathrm{N} 6$ cows (treatment $\times$ day interaction $\mathrm{F}_{2,72}=3.40 ; P$ $<0.05$; Figure 2).

\section{DISCUSSION}

The aim of our study was to investigate the effect of group size and health status on the social, feeding, and lying behavior of postpartum cows during the first $3 \mathrm{~d}$ after introduction to a group. The results provide evidence that cows experience less social competition when moved into a smaller group after calving regardless of health status. Thus, minimizing competition by housing dairy cows in a small group for the first period after calving may improve cow welfare under commer-

Table 4. The mean effect of day after introduction on feeding and social behavior recorded via feed bins and resting behavior recorded via accelerometers during the first $3 \mathrm{~d}$ after introduction (across treatments and health status)

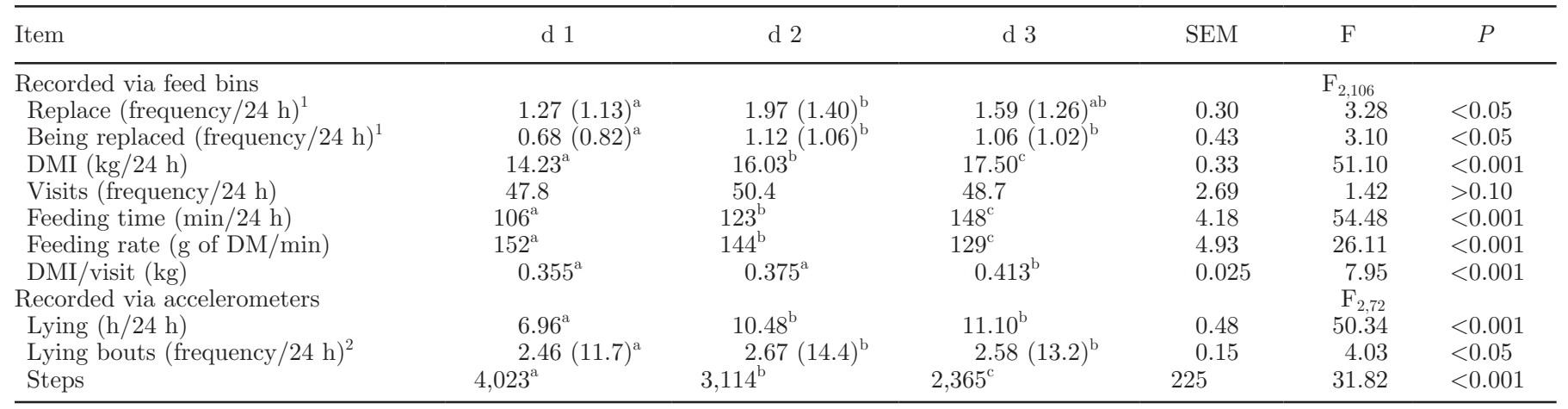

${ }^{\mathrm{a}-\mathrm{C}}$ Means within a row with different superscripts differ $(P<0.05)$.

${ }^{1}$ Transformed by square root back transformed indicated in parentheses.

${ }^{2}$ Transformed by natural logarithm back transformed indicated in parentheses. 


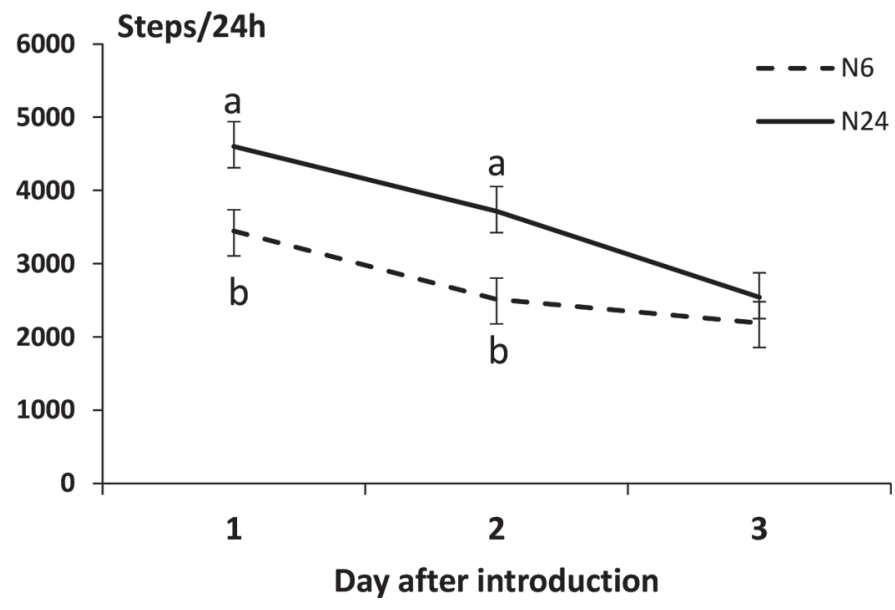

Figure 2. Number of daily steps including steps associated with milking (mean \pm SEM) of cows $(\mathrm{n}=54)$ on treatments N6 (introduced to a group of 6 cows on d 4 after calving) or N24 (introduced to a group of 24 cows on d 4 after calving). For each day different letters $(\mathrm{a}, \mathrm{b})$ indicate significant differences $(P<0.05)$ between treatments on that day.

cial conditions. Sick cows had a lower feed intake and fewer sick cows engaged in competition over freestalls, but this occurred regardless of group size. Also regardless of group size, cows had the lowest DMI and lying time during d 1 after joining the group; this response may be partially driven by the newcomer experiencing more competition and lower access to resources compared with those already in the group.

\section{Effect of Group Size on Behavior}

In the smaller groups of 6 cows, the newly introduced cows displaced and replaced fewer other cows from feed bins than in the groups of 24 on d 1 after regrouping. The lower level of agonistic behavior in the smaller group meets our hypothesis. However, it is surprising that the introduced cows initiated more displacements in the larger groups, rather than being the receiver of the displacements by resident cows. In a study where lactating cows were individually moved into an existing group of 12 cows, von Keyserlingk et al. (2008) found that the newly introduced cows were displaced from the feed more often by resident cows compared with the previous $3 \mathrm{~d}$, but no differences were noted in the number of times newly introduced cows displaced resident cows. A potential reason for the different result in our study is the design of the feed barrier; cows in our study had access to individual feed bins, whereas cows in the von Keyserlingk et al. (2008) study were fed using a post-and-rail design. In a study using the same feeding system as ours, Schirmann et al. (2011) found that prepartum cows that were newly introduced initiated more displacements on the day after regrouping. Feed barrier design has been shown to affect the number of displacements that occur in a group pen; for example, Huzzey et al. (2006) found that cows feeding from a post-and-rail system were more likely to be engaged in any displacement compared with those fed using a head lock. Although the feed bins are different from both the post-and-rail and head lock systems, they are more similar to the head locks in that they offer more protection to cows from others displacing them directly from the side or the head, and likely reduced the ability of resident cows to displace newcomers. However, this does not fully explain why the newcomers displaced other cows more often. The cows were moved at their normal feeding time, but had not been fed before being moved; perhaps the combination of the feed bin being more difficult to access combined with hunger motivated this behavior.

In addition to displacing other cows more often, cows in the larger group also visited the feed bins more often than the cows in the smaller group. This difference was not likely due to displacements from the feed bins; displacements increased from d 1 to 2, whereas visits decreased from $\mathrm{d} 1$ to 2 . The higher frequency of visits in the larger group may be driven by a greater opportunity for feed sampling and exploratory behavior compared with in the smaller groups, as more bins were available to those in the larger groups. The feed bins were filled by a robot feeder whenever less than $2 \mathrm{~kg}$ of feed was in the bin, and all cows had access to all feed bins. Dairy cows are known to sort out the smaller, energy-dense particles from their feed (DeVries et al., 2007); thus, some bins (e.g., those most recently filled) likely contained better quality feed than other bins. In a study on heifers using the same type of electronic feed bins, Huzzey et al. (2013) found that sampling behavior in heifers is affected by the quality of the feed; heifers were most likely to sample different bins more often when the energy density of their feed decreased from their previous feed. In our case, the newcomers were given the same feed they had been previously given. However, due to sorting behavior, the energy density of that feed may have been lower than what they had experienced in the individual maternity pen. As mentioned, cows in the larger pen had more bins to sample from and had a higher number of visits to the bins compared with those in the smaller group. On the third day after introduction to the pens, this difference in visits between the treatments was no longer apparent. This finding is possibly because newcomers had sampled enough to identified their preferred feed bins, or because they had identified familiar cows in the groups and formed preferential relationships. Val-Laillet et al. (2009) suggested that dairy cows prefer to compete and 
share with certain preferred individuals and that this may reduce aggression and competition over feed.

Although we found a difference in replacements recorded using video during the first day after introduction to the new pen, we only found a tendency for replacements collected automatically from the electronic feed bins to be different between treatments during the $72 \mathrm{~h}$ after introduction. This difference may be in part due to the way the data were collected. However, the definition of replacements from the videos was very similar to that used by the electronic feed bins, in that a replacement was considered when a cow replaced another cow in the feed within $10 \mathrm{~s}$ of the other cow leaving. The difference may be more likely due to the time frame when the data were measured, as cows may have been more likely to engage in replacements during the first day after introduction to the pen compared with later periods. A few more cows were included in the feed bin data, which may also have accounted for a slight difference in the results.

On the day after cows were moved into the groups of 6 cows, the newly introduced cows received less butting than those moved into the group of 24 . Cows in the smaller groups were also less likely to be involved in head-to-head fights compared with those in the larger groups. The simple explanation for this result is that in the smaller group there were fewer dominance relationships that needed to be established. In addition, these behaviors in the larger group may have been due to retaliation, as the newcomers were more likely to displace others in the group from the feed bins.

Despite these differences in social behavior, we did not find any differences between treatments in DMI, feeding time, or feeding rate. We suggest that future studies investigate other aspects of the fresh cow environment, including moving cows into very large groups $(>24)$ or moving primiparous animals into different size groups.

\section{Effect of Health on Behavior}

In the present study, poor health reduced DMI and increased latency to feed after introduction to a new pen, despite many of the cows receiving veterinary treatment, which for some cows included both an antibiotic and a pain reliever before entering the group pen. These results are consistent with other studies assessing the feed intake and social behavior of ill cows after calving. For example, Huzzey et al. (2007) found that cows with moderate and severe metritis ate less than healthy cows in the $3 \mathrm{wk}$ after calving. In a similar study, Goldhawk et al. (2009) found that cows with subclinical ketosis ate less than healthy cows during the 3 wk after calving. These 2 studies did not measure social behavior after calving, but found that cows at risk of becoming ill were less likely to be engaged in any displacements or replacements at the feed bins during the 3 wk before calving compared with healthy cows. In a study of the social behavior of ill cows after calving, Proudfoot et al. (2014) found that ill cows housed in an individual pen were more likely to hide behind a barrier dividing them from a group pen compared with healthy cows. Our results are the first of our knowledge to measure the social behavior of ill animals after entry into a new pen after calving. Although we expected more differences in social behavior, we only found that ill cows were less likely to displace other cows from lying stalls compared with healthy cows. We allotted 1 stall per cow, but due to reduced competitive ability, sick cows may have avoided competition over stalls and chosen to lie in less attractive stalls.

Overall, displacements and other agonistic behaviors at the feed bins were low in the current study compared with others; this was likely driven by the feeding system. In other studies (Huzzey et al., 2007; Goldhawk et al., 2009), cows were fed twice per day, creating 2 peak feeding times where competition for feed (and displacements at the feeding area) was highest (DeVries et al., 2004). Huzzey et al. (2007) found that cows at risk for metritis avoided feeding during these peak periods, resulting in fewer displacements compared with cows that remained healthy after calving. A potential lack of difference in displacements between sick and not sick cows could be explained by lower overall competition at the feed bins in our study compared with others.

We found no differences between the behavior of sick and not sick cows in the 2 treatments. The conditions included in the sick category were not acute and, thus, the associated behavioral changes could be expected to be typical sickness behavior (e.g., reduced feeding and social behavior). Reduced feeding is typical for hypocalcemia and fever, and has been associated with dystocia (Proudfoot et al., 2009), subclinical ketosis (Goldhawk et al., 2009), metritis (Huzzey et al., 2007), as well as mastitis (Fogsgaard, et al., 2015). Some of the included conditions have been associated with pain [metritis (Stojkov et al., 2015); mastitis (Fogsgaard et al., 2015), and digital demertitis (Pavlenko et al., 2011)], whereas other conditions (e.g., ketosis and fever) may not be associated with pain.

A main limitation with our study was the low sample size and inability to assess behavior based on the type and severity of disease. For example, in our sick category we had 9 different conditions, some of which had been treated by the herd veterinarian with an antibiotic and pain reliever, which likely aided in recovery and reduced behavioral indicators of disease, whereas others may have been unchanged or worsened. The 
general sickness response includes decreased feeding and activity while lying time is increased (Weary et al., 2009). However, the clinical conditions included in the sick category of our study may have affected behavior differently, making it more difficult to find effects of health status. For instance, mastitis reduced lying time both before and for days after treatment (Fogsgaard et al., 2015). In addition, cows with clinical ketosis have been reported to lie down more during periods with reduced management activity (Itle et al., 2015), which is a sickness response not picked up by daily averages as calculated in the present study. Finally, the effect of disease on social behavior may also depend on the animal's age. Whether different diseases affect social behavior differently is unknown. We encourage more research investigating the effect of the social environment on the behavior of sick animals and their ability to recover from the illness.

\section{Effect of Day After Introduction into a New Pen on Behavior}

From the accelerometer data, we found that the number of steps decreased over the $3 \mathrm{~d}$ regardless of treatment, but was lower among cows in the smaller groups during the first $2 \mathrm{~d}$ after introduction compared with the larger groups. The space per cow in both pens was kept consistent, but a higher number of steps in the larger group is likely due to an overall larger surface area for them to explore. However, no difference was found between treatments on $\mathrm{d} 3$, suggesting that a higher initial number of steps in the larger group may be due to a combination of exploratory behavior stimulated by the new environment, and more agonist behavior in these groups (i.e., avoidance behavior).

Lying time increased from $7 \mathrm{~h} / \mathrm{d}$ on $\mathrm{d} 1$ to about $11 \mathrm{~h} / \mathrm{d}$ on $\mathrm{d} 2$, and the number of lying bouts also increased over days. The time spent lying on $\mathrm{d} 1(7 \mathrm{~h} / \mathrm{d})$ was much lower than we expected for cows during this time period, and was likely driven by regrouping cows from the individual maternity pen into the treatment pens. Other studies have also found that regrouping cows decreases lying time (Phillips and Rind, 2001; von Keyserlingk et al., 2008); however, this drop in lying time can be mitigated by reducing the stocking density of the pen at the time of regrouping (Talebi et al., 2014). Thus, reduced stocking density may reduce some of the negative effects of regrouping. In the present study, reducing group size did not affect lying time, as cows had low lying time after regrouping regardless of treatment. More studies are needed to investigate the effect of group size on lying time over a larger range of group sizes.
Dry matter intake, feeding time, replacements, and intake per visit all increased over the $3 \mathrm{~d}$, whereas feeding rate decreased. Although increased feeding rate is a typical response to increased competition (Nielsen, 1999), we found no effect of treatment on this behavior. The increase in DMI, feeding time, and intake per visit were all likely driven by an increase in energy demand, as the cow is producing more milk, and may have also been influenced by lower competition over days. However, we noted an increase in replacements over days, which does not support the idea that competition was lower across days. In another study of regrouping, Schirmann et al. (2011) found that displacements increased from d 1 to 2 after regrouping. Similarly, von Keyserlingk et al. (2008) found that reactor displacements were highest on d 1 and 2 after regrouping; thus, the effects of regrouping are not limited to the first day, but appear to level out $3 \mathrm{~d}$ after regrouping.

\section{Parity Effects}

Second-parity cows received more butting than third- or later-parity cows. In a natural setting with stable dominance relationships, older cows maintain higher rank (Sárová et al., 2013), but frequent regroupings likely challenge the status of older cows. However, dominance is also related to BW (Landaeta-Hernández et al., 2013), and the difference between parities in the preset experiment may be due to lower BW and less experience of second-parity cows. Others have found that primiparous cows were displaced from feed bins more than multiparous cows even when correcting for BW and milk production (Neave et al., 2017), and less experience also likely plays a role.

\section{CONCLUSIONS}

Cows regrouped into a smaller group of 6 experienced less competition than cows moved into a larger group of 24 on d 4 after calving, and minimizing competition by use of small group sizes postpartum may improve cow welfare. Regardless of group size, sick cows ate less than not sick cows and were involved in less competition over freestalls. The lowest feed intake and the lowest lying time was seen on the day of introduction, underlining the importance of minimizing competition the first day after introduction to a new group in postpartum cows.

\section{ACKNOWLEDGMENTS}

Thanks to the barn staff of Aarhus University's Cattle Research facility in Foulum for animal care, and to John Misa Obidah and Erik Luc Decker (both 
at Aarhus University) for assisting with data collection and handling. K. L. Proudfoot received funding from The Aarhus University Research Foundation. The research was funded by the Danish Ministry of Food, Agriculture and Fisheries (Copenhagen, Denmark).

\section{REFERENCES}

Bossen, D., M. R. Weisbjerg, L. Munksgaard, and S. Højsgaard. 2009 Allocation of feed based on individual dairy cow live weight changes I: Feed intake and live weight changes during lactation. Livest. Sci. 126:252-272.

Burow, E., T. R. Nielsen, U. Halekoh, and U. Knierim. 2009. Social interactions of dairy cows introduced postpartally to a separated barn section-Pilot study. Acta Agric. Scand. A Anim. Sci. 59:192-196.

Chapinal, N., D. M. Veira, D. M. Weary, and M. A. G. von Keyserlingk. 2007. Technical note: Validation of a system for monitoring individual feeding and drinking behavior and intake in grouphoused cattle. J. Dairy Sci. 90:5732-5736.

DeVries, T. J., K. A. Beauchemin, and M. A. G. von Keyserlingk. 2007. Dietary forage concentration affects the feed sorting behavior of lactating dairy cows. J. Dairy Sci. 90:5572-5579.

DeVries, T. J., M. A. G. von Keyserlingk, and D. M. Weary. 2004. Effect of feeding space on the inter-cow distance, aggression and feeding behaviour of free-stall housed lactating dairy cows. J. Dairy Sci. 87:1432-1438.

Fogsgaard, K. K., T. W. Bennedsgaard, and M. S. Herskin. 2015. Behavioral changes in freestall-housed dairy cows with naturally occurring clinical mastitis. J. Dairy Sci. 98:1730-1738.

Goldhawk, C., N. Chapinal, D. M. Veira, D. M. Weary, and M. A. G. von Keyserlingk. 2009. Prepartum feeding behavior is an early indicator of subclinical ketosis. J. Dairy Sci. 92:4971-4977.

Huzzey, J. M., T. J. DeVries, P. Valois, and M. A. G. von Keyserlingk. 2006. Stocking density and feed barrier design affects feeding and social behavior of dairy cattle. J. Dairy Sci. 89:126-133.

Huzzey, J. M., D. M. Veira, D. M. Weary, and M. A. G. von Keyserlingk. 2007. Prepartum behavior and dry matter intake measures identify cows at risk for metritis. J. Dairy Sci. 90:3220-3233.

Huzzey, J. M., J. A. Fregonesi, M. A. G. von Keyserlingk, and D. M. Weary. 2013. Sampling behavior of dairy cattle: Effects of variation in dietary energy density on behavior at the feed bunk. J. Dairy Sci. 96:247-256.

Huzzey, J. M., D. M. Weary, B. Y. F. Tiau, and M. A. G. von Keyserlingk. 2014. Short communication: Automatic detection of social competition using an electronic feeding system. J. Dairy Sci. 97:2953-2958.

Itle, A. J., J. M. Huzzey, D. M. Weary, and M. A. G. von Keyserlingk. 2015. Clinical ketosis and standing behavior in transition cows. J. Dairy Sci. 98:128-134.

Iwersen, M., U. Falkenberg, R. Voigtsberger, D. Forderung, and W. Heuwieser. 2009. Evaluation of an electronic cowside test to detect subclinical ketosis in dairy cows. J. Dairy Sci. 92:2618-2624.

Jensen, M. B. 2004. Computer controlled milk feeding of dairy calves: The effects of number of calves per feeder and number of milk portions on use of feeder and social behavior. J. Dairy Sci. 87:34283438 .

Jensen, M. B., and M. Budde. 2006. The effect of milk feeding method and group size on feeding behavior and cross-sucking in grouphoused dairy calves. J. Dairy Sci. 89:4778-4783.
Landaeta-Hernández, A. J., D. O. Rae, M. Kaske, and L. F. Archbald. 2013. Factors influencing social organization in postpartum Angus cows under confinement. Effect on cow-calf weight change. Livest. Sci. $152: 47-52$.

Mulligan, F. J., and M. L. Doherty. 2008. Production Diseases of the Transition Cow. Vet. J. 176:3-9.

Neave, H. W., J. Lomb, M. A. G. von Keyserlingk, A. Behnam-Shabahang, and D. M. Weary. 2017. Parity differences in the behavior of transition dairy cows. J. Dairy Sci. 100:548-561.

Nielsen, B. L. 1999. On the interpretation of feeding behaviour measures and the use of feeding rate as an indicator of social constraint. Appl. Anim. Behav. Sci. 63:79-91.

Østergaard, S., P. T. Thomsen, and E. Burow. 2010. Separate housing for one month after calving improves production and health in primiparous cows but not in multiparous cows. J. Dairy Sci. 93:3533-3541.

Pavlenko, A., C. Bergsten, I. Ekesbo, T. Kaart, A. Aland, and L. Lidfors. 2011. Influence of digital dermatitis and sole ulcer on dairy cow behaviour and milk production. Animal 5:1259-1269.

Phillips, C. J. C., and M. I. Rind. 2001. The effects on production and behavior of mixing uniparous and multiparous cows. J. Dairy Sci. 84:2424-2429.

Proudfoot, K. L., J. M. Huzzey, and M. A. G. von Keyserlingk. 2009 The effect of dystocia on the dry matter intake and behavior of Holstein cows. J. Dairy Sci. 92:4937-4944.

Proudfoot, K. L., M. B. Jensen, D. M. Weary, and M. A. G. von Keyserlingk. 2014. Dairy cows seek isolation at calving and when ill. J. Dairy Sci. 97:2731-2739.

Rind, M. I., and C. J. C. Phillips. 1999. The effect of group size on the ingestive and social behaviour of grazing dairy cows. Anim. Sci. 68:589-596.

Sárová, R., M. Spinka, I. Stehulová, F. Ceacero, M. Simecková, and R. Kotrba. 2013. Pay respect to the elders: age, more than body mass, determines dominance in female beef cattle. Anim. Behav. 86:1315-1323.

Schirmann, K., N. Chapinal, D. M. Weary, W. Heuwueser, and M. A G. von Keyserlingk. 2011. Short-term effects of regrouping on behavior of prepartum dairy cows. J. Dairy Sci. 94:2312-2319.

Stojkov, J., M. A. G. von Keyserlingk, J. N. Marchant-Forde, and D. M. Weary. 2015. Assessment of visceral pain associated with metritis in dairy cows. J. Dairy Sci. 98:5352-5361.

Talebi, A., M. A. G. von Keyserlingk, E. Telezhenko, and D. M. Weary. 2014. Reduced stocking density mitigates the negative effects of regrouping in dairy cattle. J. Dairy Sci. 97:1358-1363.

Telezhenko, E., M. A. G. von Keyserlingk, A. Talebi, and D. M. Weary. 2012. Effect of pen size, group size, and stocking density on activity in freestall-housed dairy cows. J. Dairy Sci. 95:3064-3069.

Val-Laillet, D., V. Guesdon, M. A. G. von Keyserlingk, A. M. De Passillé, and J. Rushen. 2009. Allogrooming in cattle: Relationships between social preferences, feeding displacements and social dominance. Appl. Anim. Behav. Sci. 116:141-149.

von Keyserlingk, M. A. G., D. Olineck, and D. M. Weary. 2008. Acute behavioral effects of regrouping dairy cows. J. Dairy Sci. 91:10111016.

Weary, D. M., J. M. Huzzey, and M. A. G. von Keyserlingk. 2009. Board-Invited Review: Using behavior to predict and identify il health in animals. J. Anim. Sci. 87:770-777. 